\title{
O PARADOXO DO DESENVOLVIMENTO: MINERAÇÃO, DESLOCAMENTOS COMPULSÓRIOS E A VIDA COTIDIANA EM CATEME, MOATIZE, MOÇAMBIQUE
}

\begin{abstract}
Albino José Eusébio ${ }^{1}$
O presente ensaio fotográfico tem o objetivo de convidar o (a) leitor (a) a mergulhar visualmente na realidade de vida cotidiana das famílias compulsoriamente deslocadas pelo projeto Moatize de exploração de carvão mineral, operado pela multinacional brasileira Vale no distrito de Moatize, Província de Tete, região central de Moçambique. As imagens resultam de uma pesquisa de campo doutoral realizada na comunidade de Cateme, posto administrativo de Kambulatsitsi, Distrito de Moatize, no primeiro semestre de 2016 e segundo semestre de 2017 - mais de 10 anos após a instalação projeto.

Inspirada na sociologia do cotidiano (Martins, 1998; 2014), a pesquisa buscou compreender através da observação e das narrativas das próprias populações, as experiências vividas desde o anúncio da chegada da multinacional brasileira na região; as ações desenvolvidas após a chegada da empresa; o processo de deslocamento; a chegada em Cateme e a realidade atual de vida cotidiana. Ou seja, procurou-se, tendo como inspiração a proposta de Veena Das (2008), compreender como o processo de deslocamento compulsório foi experienciado e é cotidianamente vivido pelas próprias famílias compulsoriamente deslocadas.
\end{abstract}

A vida dessas famílias ganha uma nova fase na sua trajetória biográfica quando em 2004, a multinacional brasileira Vale ganhou o concurso internacional promovido pelo governo moçambicano para a exploração das minas de Moatize, vencendo empresas como a BHP billiton e a Rio Tinto, algumas das maiores mineradoras do mundo. A vitória da Vale, não só abriu espaço para entrada do primeiro grande investimento direto brasileiro no estado pós-colonial moçambicano, como também transformou o distrito de Moatize no espaço onde, seguindo a concepção de Walter Mignolo (2003), projetos globais inerentes à

\footnotetext{
${ }^{1}$ Universidade Federal do Rio de Janeiro, Brasil. Email: albinoeusebio@outlook.com ORCID id: https://orcid.org/0000-0001-5646-6190
}

Iluminuras, Porto Alegre, v. 21, n. 54, p. 862-870, setembro, 2020. 
expansão internacional do capital se interceptam de forma violenta com histórias e modos de vida das populações locais.

Aproximadamente mil e quinhentas famílias foram compulsoriamente deslocadas das suas terras de ocupação no processo de instalação da mina de "dinamitação" a céu aberto. Na comunidade de Cateme, que foi o meu lócus central da pesquisa, foram realocadas as famílias classificadas de rurais. Evidências etnográficas mostram que o processo de deslocamento compulsório foi marcado por falsas promessas, cooptação e violação de direitos. Não havia uma preocupação com o destino das pessoas e a continuidade integral das suas lógicas de produção, organização e reprodução socioeconômica e cultural, mas sim, com a sua saída do local para dinamizar a exploração do carvão e multiplicação do capital. O autoritarismo, a tutela e o "negligenciamento" dos projetos e modos de vida das diversas famílias atingidas, expropriadas ou não, marcaram e continuam marcando o processo do controle do território por parte da multinacional, numa autêntica reedição para o tempo presente de práticas violentas do estilo colonial.

As narrativas sobre a realidade de vida cotidiana em Cateme, mostram que o deslocamento compulsório desestruturou de forma significativa os seus modos originais de reprodução social, econômica e cultural. O grau dessa desestruturação varia de acordo com a trajetória de vida de cada família.

Aqui vivo uma situação de sofrimento, como já perdi meu marido a situação fica pior. La pelo menos tinham muitos recursos que nos ajudavam a superar situações de crise. Se a empresa pelo menos um dia falar para a gente voltar às nossas terras, eu sou uma das pessoas que voltaria sem nenhum receio, porque lá estava a viver melhor. ${ }^{2}$

O deslocamento provocou também uma ruptura na relação com espaços de peculiar significância simbólica. “Como a Vale ainda não começou a explorar lá [Malábue], saindo daqui posso vos indicar onde foi enterrado o meu cordão umbilical". ${ }^{3}$

De fato, a realidade de vida cotidiana em Cateme escancara a violência das práticas empresariais e denuncia o paradoxo do desenvolvimento. Porém, num processo de

${ }^{2}$ Sra. F.C. Malábue - moradora do bairro Malábue, Comunidade de Cateme: entrevista realizada no dia 19 de março de 2016.

${ }^{3}$ Idem 
afirmação local da cidadania, as populações de Cateme se engajam em ações coletivas de resistências em defesa dos seus direitos. Seja através da carta denúncia e acampamento em frente à sede do governo distrital, seja através do bloqueio da estrada de ferro que passa a escassos metros da comunidade e por onde os pesados trens transportam o carvão mineral para os portos do oceano indico. Ao denunciar a vulnerabilidade e o sofrimento social (Magalhães, 2007; Zhouri et al, 2016) que caracteriza a realidade de vida cotidiana nos "novos lugares", essas ações coletivas locais de resistência apresentam também narrativas outras para uma reflexão crítica sobre a atual lógica de desenvolvimento em Moçambique baseada na exploração e exportação de commodities.

A comunidade de Cateme se transformou num campo de resistência, num lugar de práticas contra-hegemônicas (Escobar, 2005a; 2005b), ou ainda, num lugar de contestação de projetos globais ligados à expansão internacional do capital que se interceptam de forma violenta com histórias e modos de vida das populações locais (Mignolo, 2003). Importa frisar que as ações de resistência em Cateme não se resumem exclusivamente em ações de protestos e confrontos. Tão significativas são também as ações cotidianas de ressignificação da vida e a busca de novos campos de reprodução social e econômica.

Agora sou motoqueiro, com esse trabalho busco complementar a renda do trabalho na machamba [nome dado a porção de terra onde se pratica, por exemplo, a agricultura familiar] já que tem uma produção fraca por causa da baixa qualidade das terras daqui... ${ }^{4}$

Seja como motoqueiro ou com uma feirinha de venda de tomate nas ruas mais movimentadas da comunidade, as populações realocadas em Cateme se engajam em novos campos de possibilidades de sobrevivência cotidiana, se negam a serem cúmplices do aniquilamento da sua própria existência, denunciam a violência da expropriação e se afirmam como sujeitos da sua própria história e trajetória de vida. A ressignificação da vida e a busca de novos campos de possibilidade de sobrevivência é uma forma de (r)existência.

${ }^{4}$ Sr. E.M.T. Chipanga - morador do bairro Chipanga, Comunidade de Cateme: entrevista realizada no dia 14 de março de 2016. 
As imagens fotográficas a seguir introduzem-nos nessa nova dinâmica de vida cotidiana em Cateme, na qual convido o(a) leitor(a) a mergulhar visualmente. ${ }^{5}$

Figura 1 - Na parte externa do mercado de Cateme construída pela empresa proliferam novas bancas (feiras e feirinhas) para venda de produtos diversos.

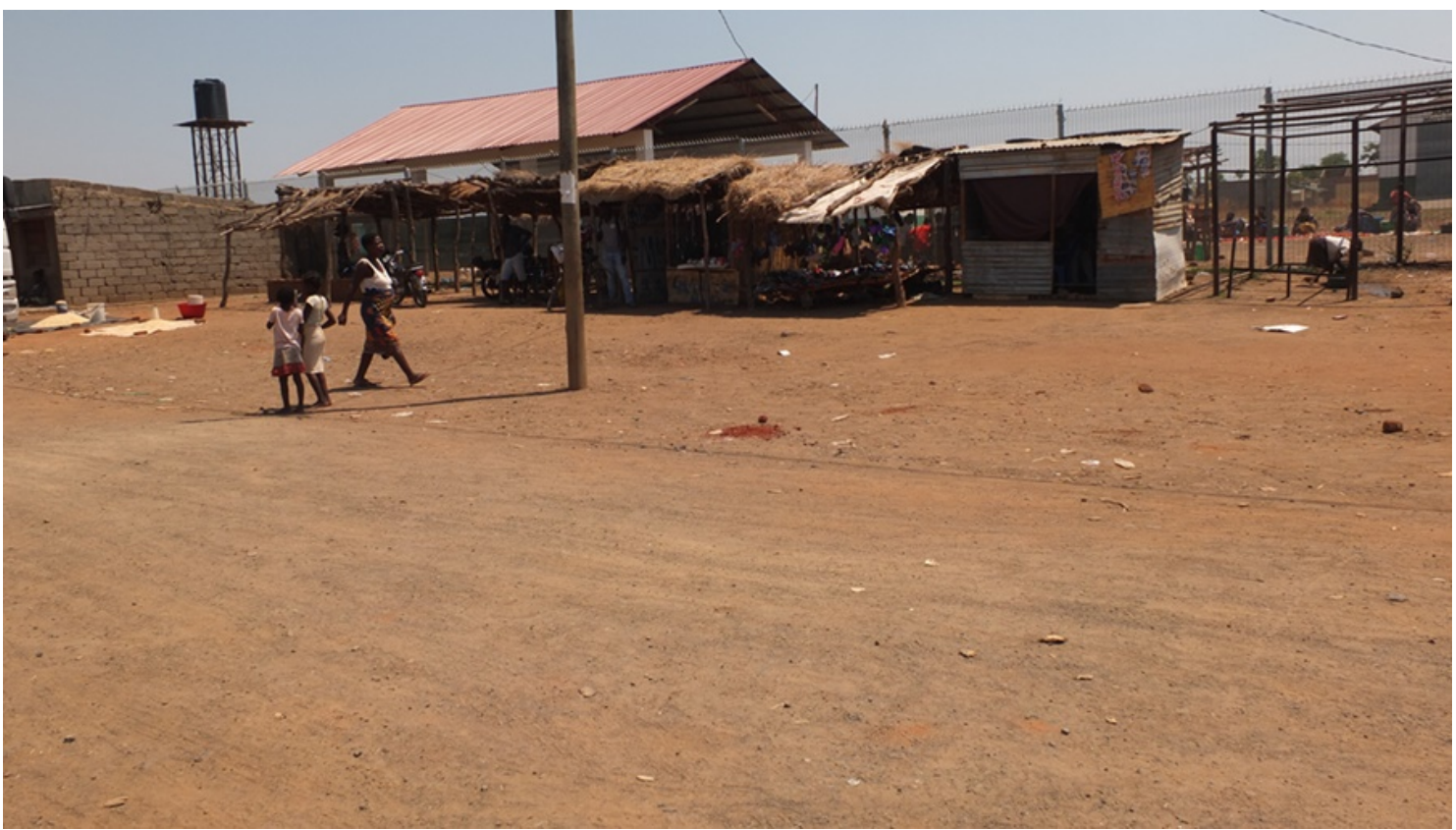

Fonte: Arquivo Pessoal, 2017.

${ }^{5}$ Todas as imagens foram tiradas pelo autor com recurso a uma máquina fotográfica da marca Fujifilm X-S1, durante as duas fases da pesquisa doutoral em Cateme.

Iluminuras, Porto Alegre, v. 21, n. 54, p. 862-870, setembro, 2020. 
Figura 2 - Muitas das bancas são fixas, outras são moveis o que permite que mudem de espaço com facilidade. As bancas moveis são mais usadas para a venda de variados tipos farinhas e produtos agrícolas.

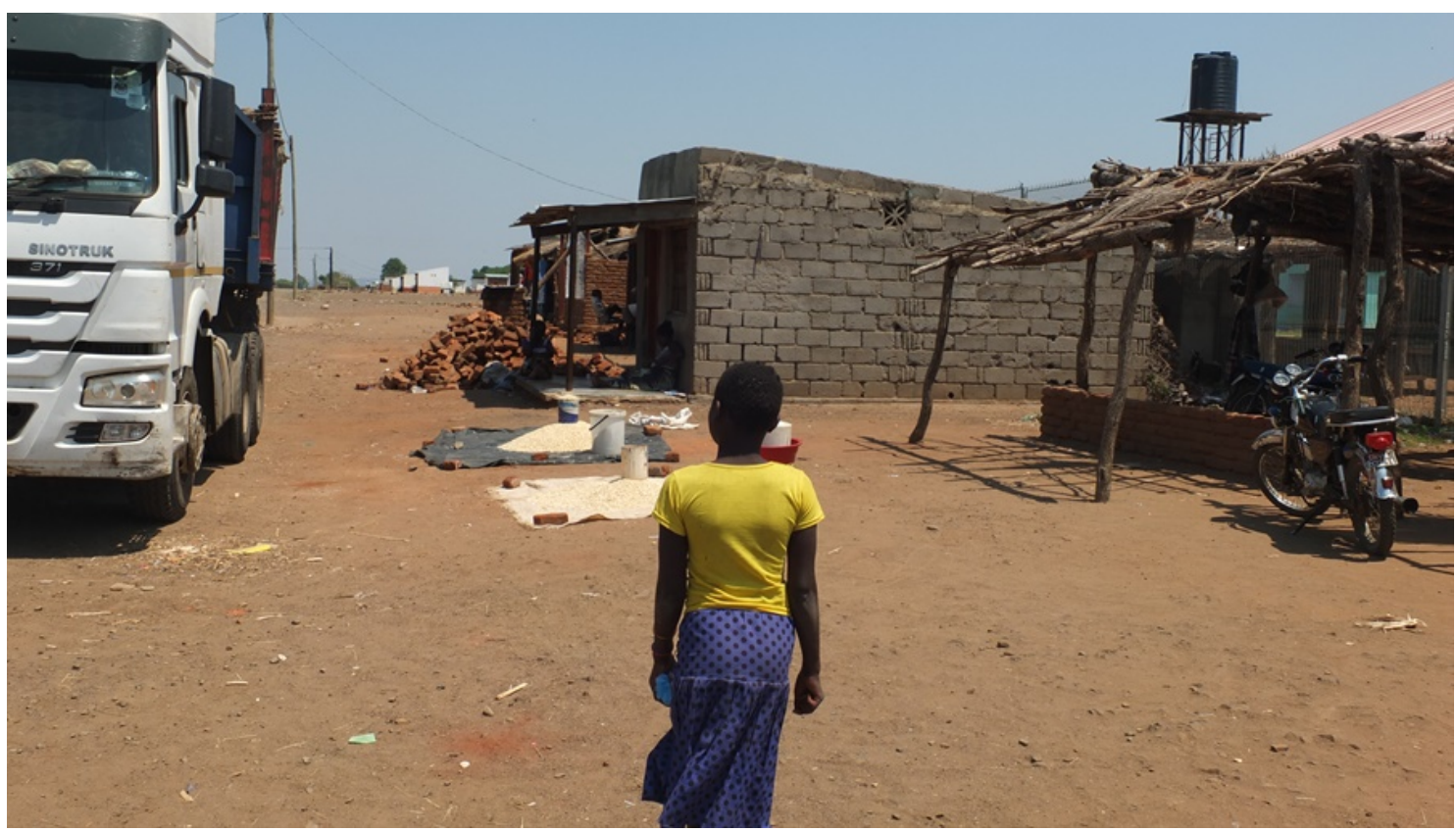

Fonte: Arquivo Pessoal, 2017.

Figura 3 - Algumas dessas novas bancas apresentam investimentos maiores em infraestruturas e diversidade de ofertas. Nessas "bancas maiores" proliferam produtos mais industrializados.

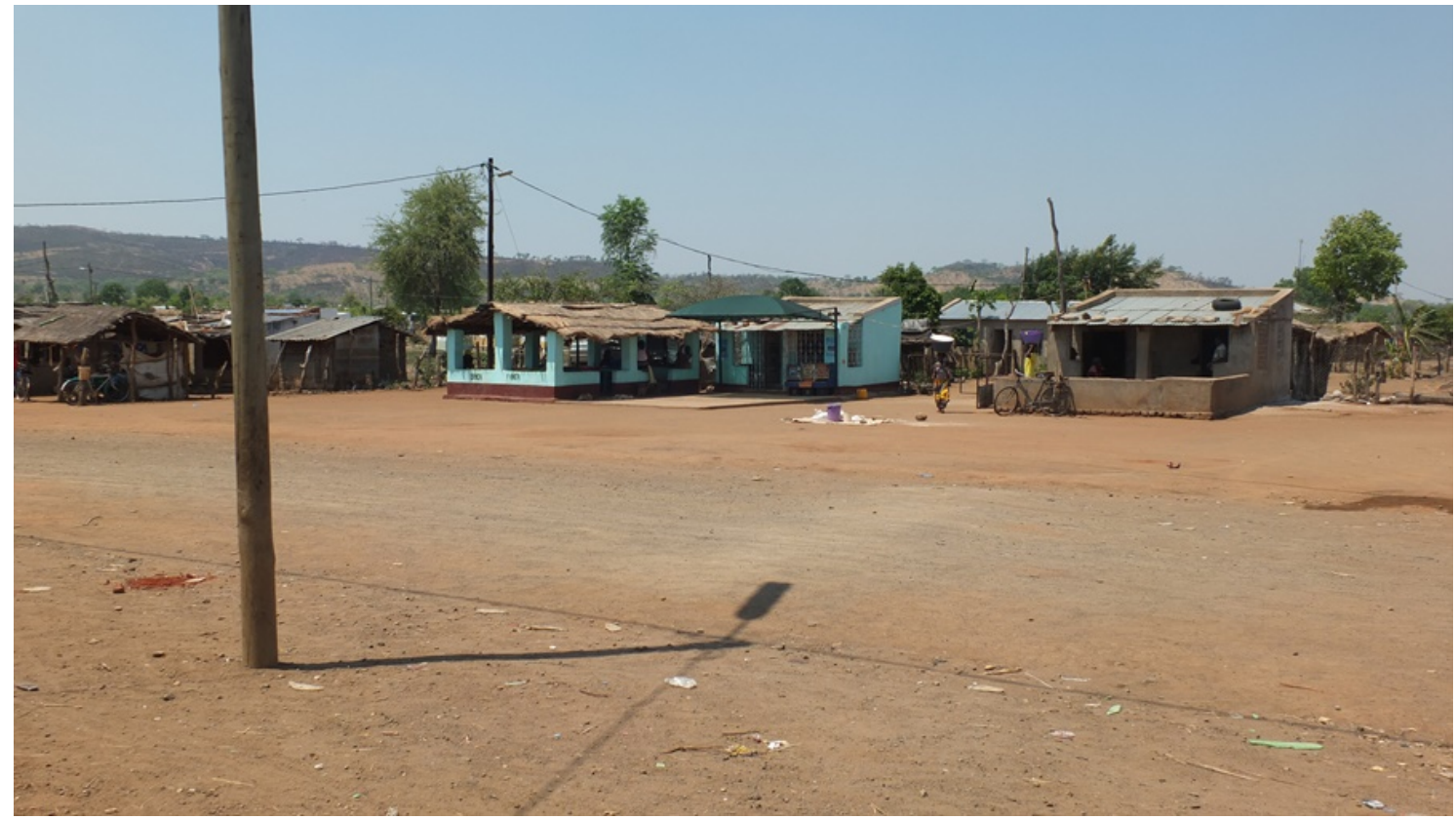

Fonte: Arquivo Pessoal, 2017

Iluminuras, Porto Alegre, v. 21, n. 54, p. 862-870, setembro, 2020. 
Figura 4 - Em busca de melhoria das condições de subsistências alguns moradores investiram no processo de produção de frangos. Essa atividade foi incentivada pela empresa, como complementar a produção agrícola, porém os resultados não têm, segundo os moradores, sido animadores. De fato, um número significativo de moradores desistiu da atividade.

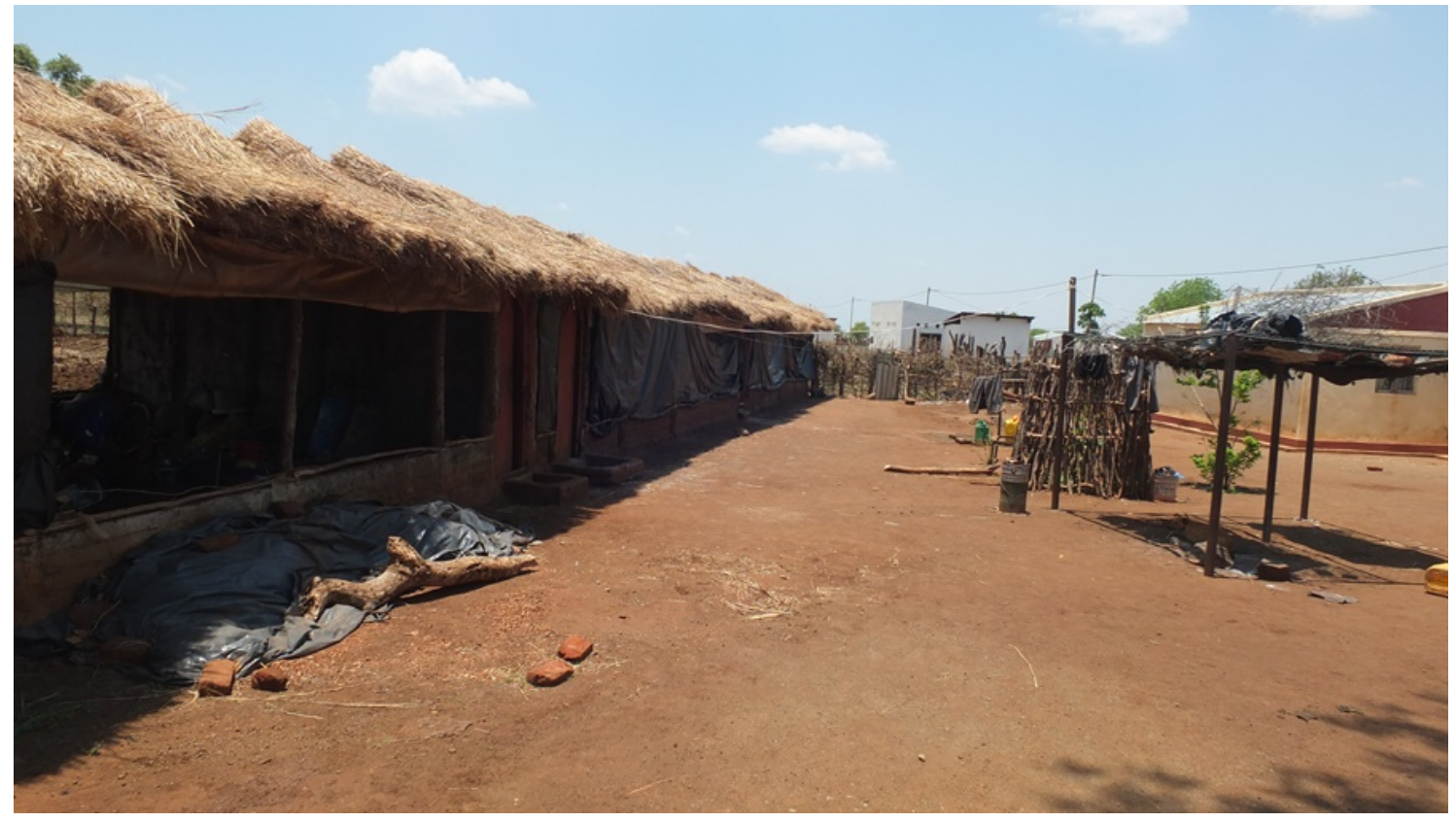

Fonte: Arquivo Pessoal, 2017.

Figura 5 - As bancas, fixas ou moveis, proliferam também nas ruas mais movimentadas da comunidade.

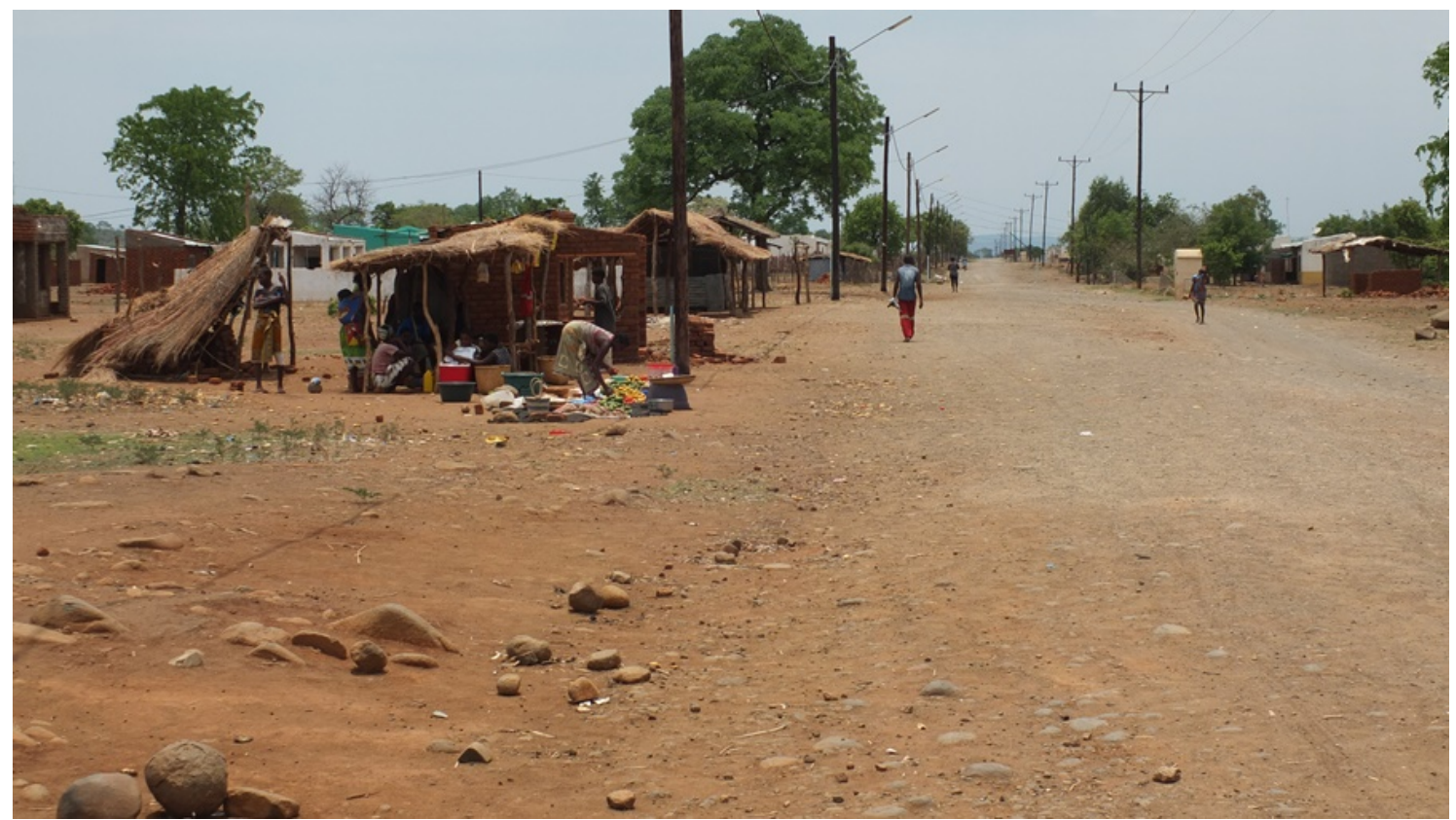

Fonte: Arquivo Pessoal, 2017.

Iluminuras, Porto Alegre, v. 21, n. 54, p. 862-870, setembro, 2020. 
Figura 6 - A oferta é tal como na área do mercado diversificada, tomate, cebola etc. Nas bancas fixas existe também uma significativa oferta de produtos industrializados.

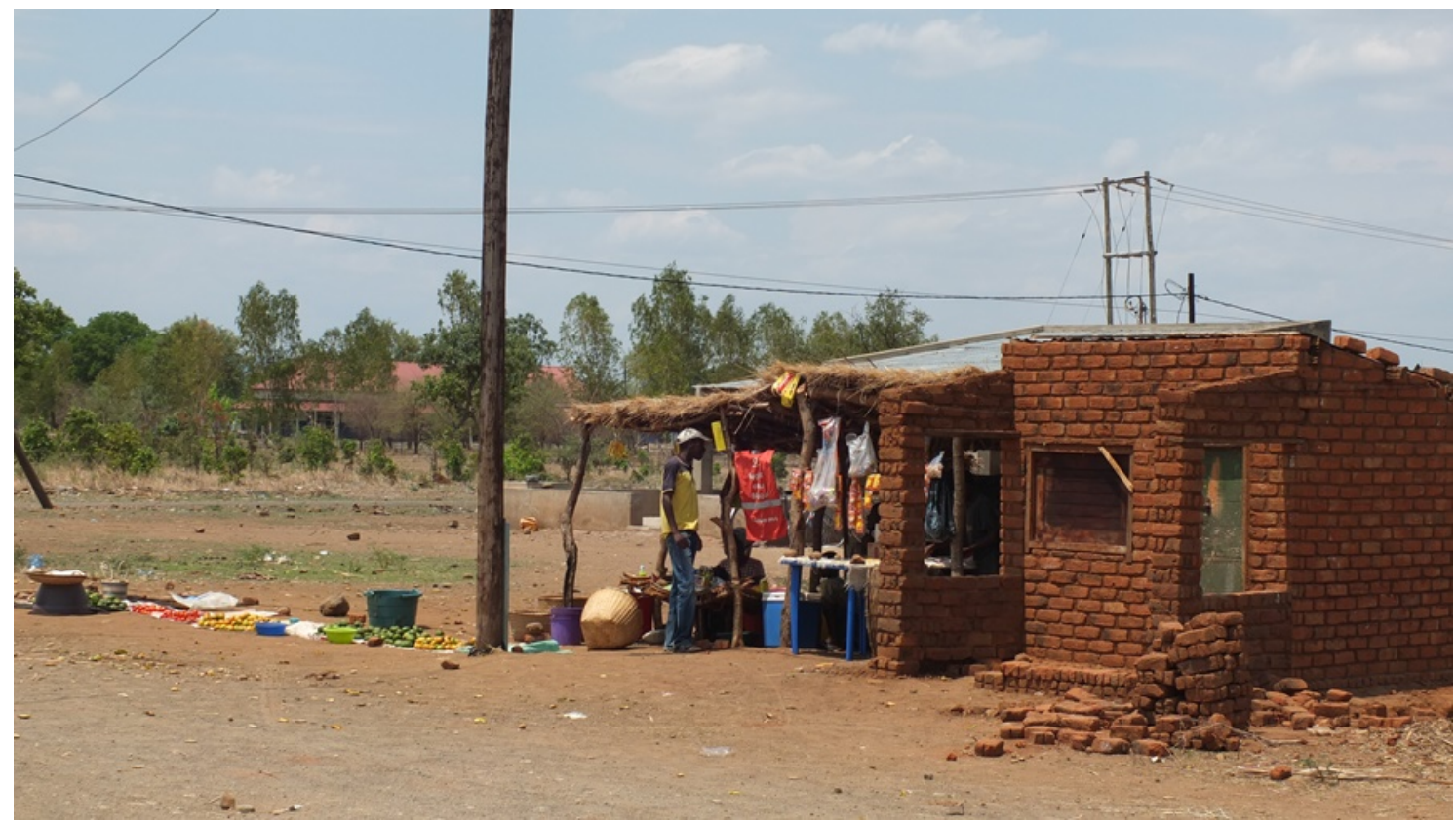

Fonte: Arquivo Pessoal, 2017.

Figura 7 - Outra atividade que prolifera na comunidade de Cateme é de mototaxistas. "carregar pessoas daqui e para ali".

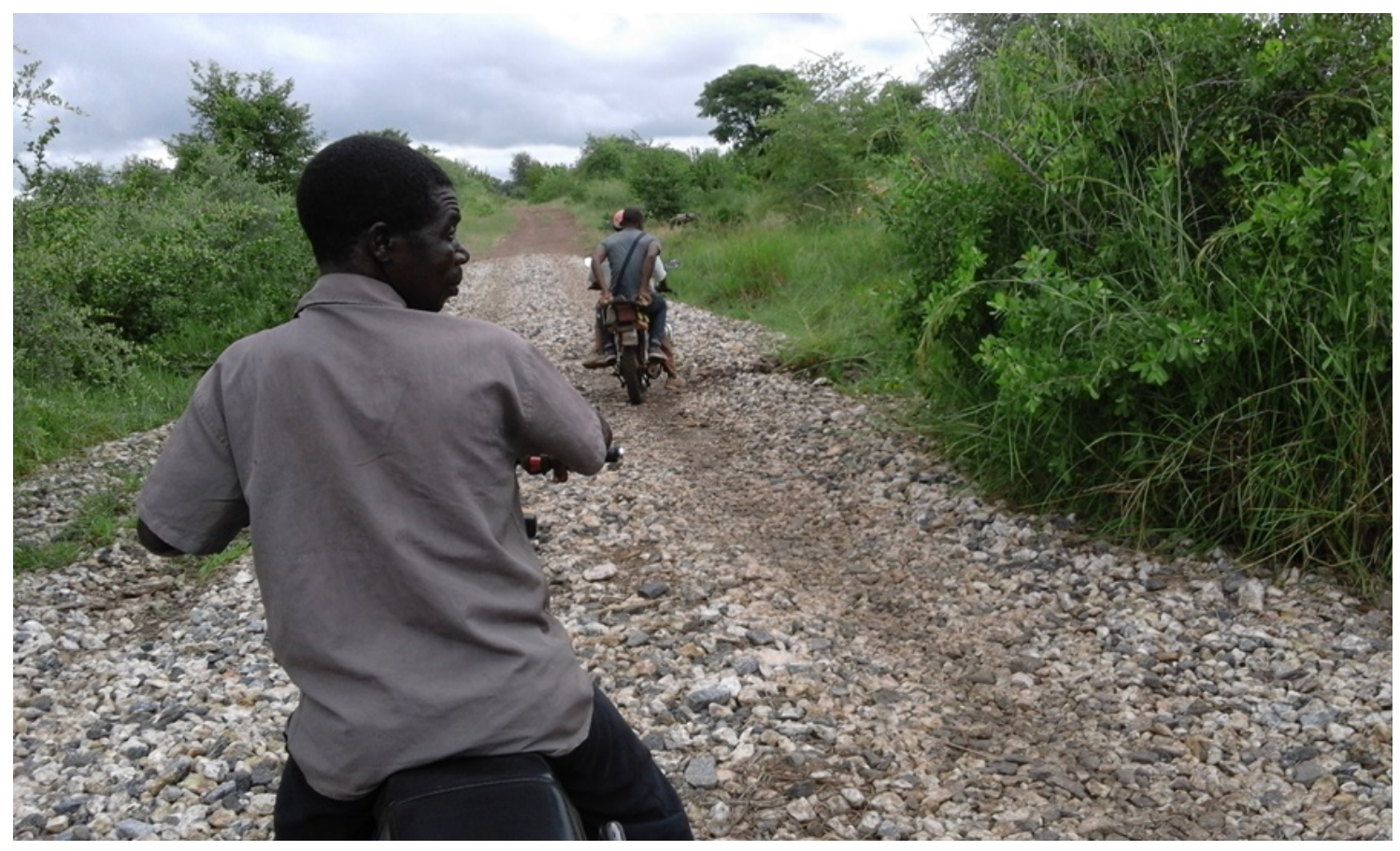

Fonte: Arquivo Pessoal, 2016.

Iluminuras, Porto Alegre, v. 21, n. 54, p. 862-870, setembro, 2020. 
Figura 8 - O mercado é o principal ponto de chegada e partida dos mototaxistas. Isso deve-se em parte por ser uma área de integração. É de lá onde partem os chapas (uma espécie de van muito usada em Moçambique para o transporte público de passageiros) para a vila de Moatize.

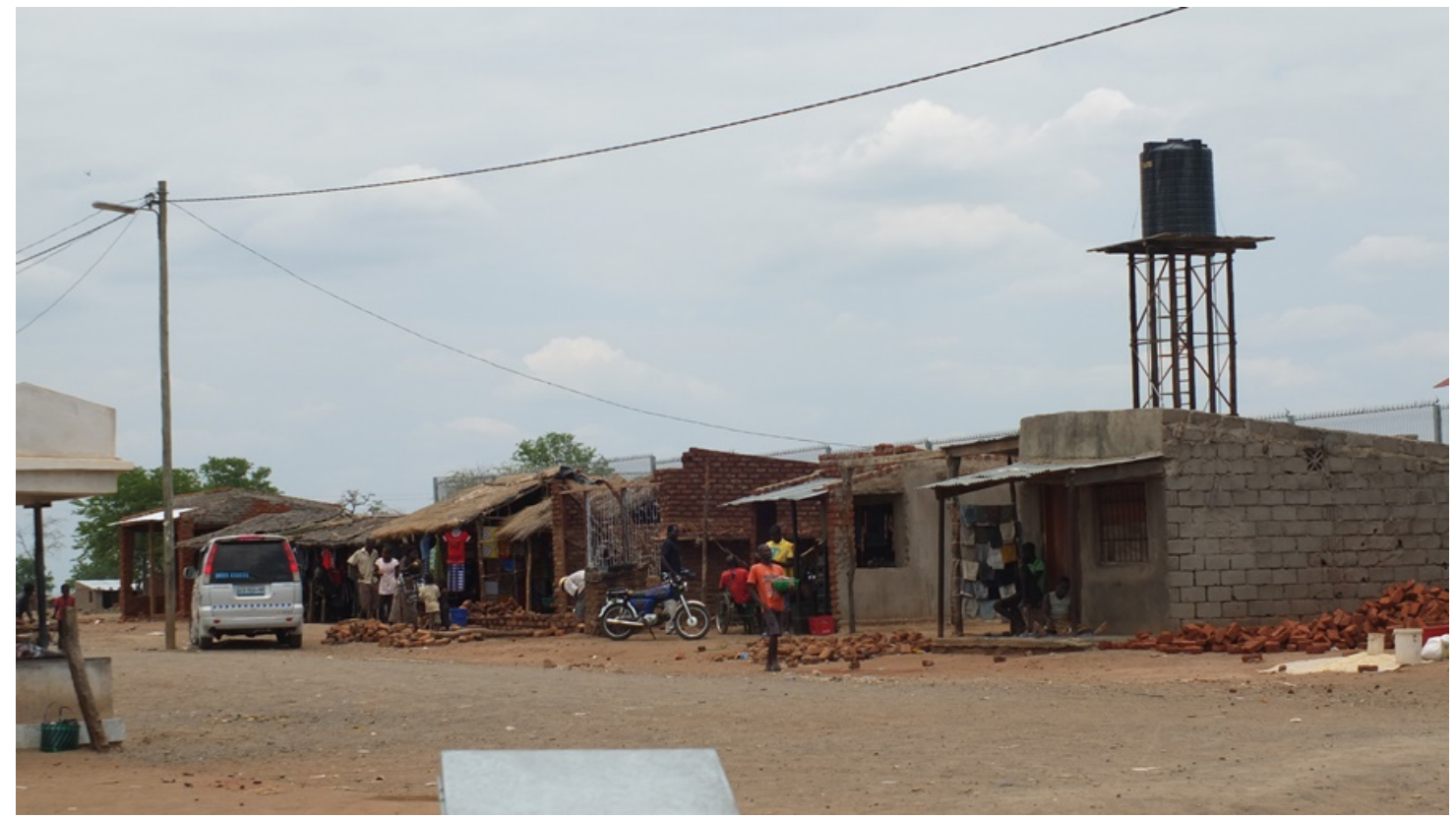

Fonte: Arquivo Pessoal, 2017.

Figura 9 - É quase impossível chegar no mercado e não encontrar uma moto, umas são para o uso particular, mas muitas estão "lá" para "carregar pessoas daqui para ali...Cateme é uma área imensa. Com essas motos percorri durante o trabalho de campo diversas áreas da comunidade.

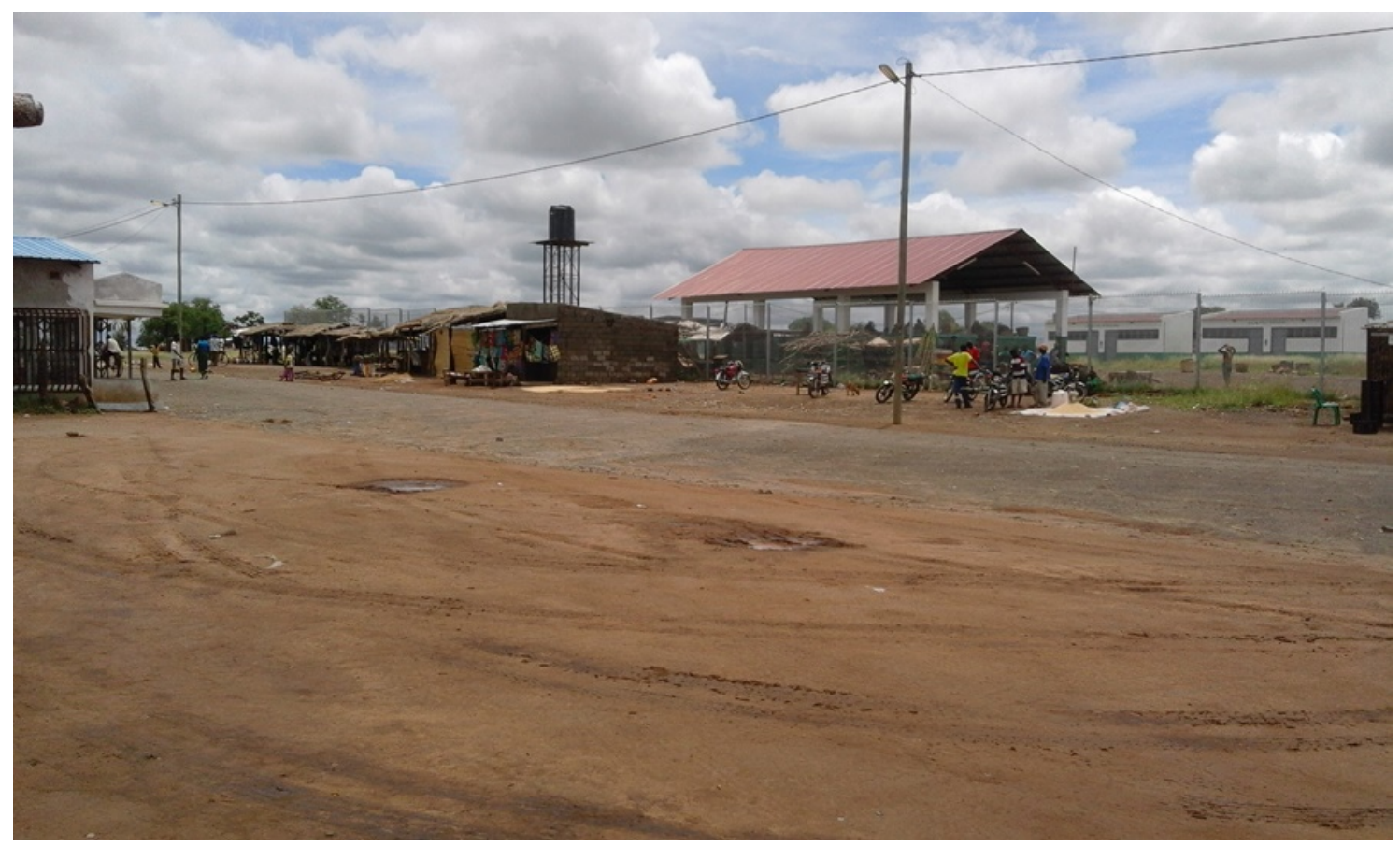

Fonte: Arquivo Pessoal, 2016.

Iluminuras, Porto Alegre, v. 21, n. 54, p. 862-870, setembro, 2020. 


\section{REFERÊNCIAS}

DAS, Veena. Sujetos del dolor, agentes de dignidad. Bogotá, Universidad Nacional de Colombia. Facultad de Ciencias Humanas: Pontificia Universidad Javeriana, Instituto Pensar, 2008.

ESCOBAR, Arturo. Imagining a post-development era? In: EDELMAN, Marc; HAUGERUD, Angelique. (org.). The anthropology of development and globalization: from classical political economy to contemporary neoliberalism. Malden, Blackwell Publishing, 2005b, p. 341-351.

ESCOBAR, Arturo. O lugar da natureza e a natureza do lugar: globalização ou pósdesenvolvimento? In: LANDER, Edgardo. (org.): A colonialidade do saber: eurocentrismo e ciências sociais. Perspectivas latino-americanas. Buenos Aires, Colección Sur-Sur, CLACSO, 2005a, p.133-168.

MAGALHÃES, Sônia B. Lamento e Dor. Uma análise sócio-antropológica do deslocamento compulsório provocado pela construção de barragens. 2007. Tese (Doutorado em Antropologia Social) - Programa de Pós-Graduação em Ciências Sociais da Universidade Federal do Pará em co-tutela com a École Doctorale Vivant et Sócietés da Universidade Paris 13, Belém, 2007.

MARTINS, José de Sousa. Uma sociologia da vida cotidiana: ensaios na perspectiva de Florestan Fernandes, de Wright Mills e de Henri Lefebvre. São Paulo, Contexto, 2014.

MARTINS, José de Sousa. O senso comum e a vida cotidiana. Tempo Social, São Paulo, vol. 10, n. 01, p. 1-8, 1998.

MIGNOLO, Walter. Histórias locais/projetos globais: colonialidade, saberes subalternos e pensamento liminar. Belo Horizonte, Ed. UFMG, 2003.

ZHOURI, Andréa et al. O desastre de Mariana: colonialidade e sofrimento social. In: ZHOURI, Andréa; BOLADOS, Paola; CASTRO, Edna. (org.). Mineração na América do Sul: neoextrativismo e lutas territoriais. São Paulo, Annablume, 2016, p. 45-66.

Recebido: $15 / 10 / 2019$

Aprovado: 04/09/2020 